\title{
Biological implications of longevity in dairy cows: 2. Changes in methane emissions and efficiency with age
}

\author{
F. Grandl, ${ }^{*}$ S. L. Amelchanka, ${ }^{*}$ M. Furger,† M. Clauss,ł J. O. Zeitz,§ M. Kreuzer, ${ }^{* 1}$ and A. Schwarm* \\ ${ }^{*}$ ETH Zurich, Institute of Agricultural Sciences, Universitaetstrasse 2, 8092 Zurich, Switzerland \\ †Agricultural Education and Advisory Centre Plantahof, Kantonsstrasse 17, 7302 Landquart, Switzerland \\ łUniversity of Zurich, Vetsuisse Faculty, Clinic for Zoo Animals, Exotic Pets and Wildlife, Winterthurerstrasse 260, 8057 Zurich, Switzerland \\ §Justus-Liebig-University Gießen, Institute of Animal Nutrition and Nutritional Physiology, Heinrich-Buff-Ring 26-32, 35392 Gießen, Germany
}

\begin{abstract}
Previous studies indicated that absolute $\mathrm{CH}_{4}$ emissions and $\mathrm{CH}_{4}$ yield might increase and that milk production efficiency might decrease with age in cattle. Both would make strategies to increase longevity in dairy cattle less attractive. These aspects were experimentally determined in Brown Swiss cattle distributed continuously across a large age range. Thirty lactating dairy cows (876-3,648 d of age) received diets consisting of hay, corn silage, and grass pellets supplemented with 0 or $5 \mathrm{~kg}$ of concentrate per day. Twelve heifers (199-778 d of age) received hay only. Cows and heifers were members of herds subjected to the 2 different feeding regimens (with or without concentrate) for the past 10 yr. Methane emissions were measured individually for $2 \mathrm{~d}$ in open-circuit respiration chambers, followed by quantifying individual feed intake and milk yield over $8 \mathrm{~d}$. Additional data on digestibility, rumination time, and passage time of feed of all experimental animals were available. Regression analyses were applied to evaluate effects of age and feeding regimen. Body weight, milk yield, and the hay proportion of forage dry matter intake were considered as covariates. Methane emissions per unit of intake, body weight, and milk yield were significantly related to age. Their development in the cows with age was characterized by an increase to maximum at around 2,000 d of age, followed by a decline. This response was not accompanied by corresponding age-related changes in intake, chewing activity, digesta passage time, and digestibility of organic matter, which would have explained shifts in $\mathrm{CH}_{4}$. However, fiber digestibility showed a similar change with age as methane emissions, resulting in quite stable methane emissions per unit of digestible fiber. As expected, methane emissions intensity per unit of milk produced was greater by $8 \%$ without con-
\end{abstract}

Received August 15, 2015.

Accepted January 12, 2016

${ }^{1}$ Corresponding author: michael.kreuzer@inw.agrl.ethz.ch centrate than with concentrate, but no difference was noted in the response to age when the animals were subjected to different feeding regimens. The efficiency of milk production was only marginally influenced by age and diet, and no different response was observed for age in the 2 dietary regimens. In conclusion, life cycle analyses of milk production systems focusing on longevity should consider changing methane yields with age in addition to the variation in environmental costs for replacements of culled cows.

Key words: greenhouse gas, lactation number, residual feed intake, forage-based diet, feed efficiency

\section{INTRODUCTION}

The contribution of methane emissions from ruminants to global greenhouse gas (GHG) budgets is substantial (e.g., FAOSTAT, 2014). The current search for efficient mitigation measures focuses on nutritional strategies (e.g., Beauchemin et al., 2008; Hristov et al., 2013a,b) and on animal breeding measures (e.g., Hristov et al., 2013b; Pinares-Patiño et al., 2013). Research activities mostly aim at reducing $\mathrm{CH}_{4}$ emissions in relation to actual milk yield $\left(\mathrm{CH}_{4}\right.$ emission intensity) and less so on strategies affecting entire dairy production systems. Milk production by dairy cows has undergone a remarkable increase, which is often sustained with increasing amounts of concentrate. This helps to reduce enteric $\mathrm{CH}_{4}$ emission intensity further (discussed in Beauchemin et al., 2008), even when considering the concomitantly increased manure-derived $\mathrm{CH}_{4}$ amounts (Hindrichsen et al., 2006). However, the concentrate production results in substantial GHG emissions (Thomassen et al., 2008). This counteracts its mitigating effect in enteric emissions (O'Brien et al., 2012). Furthermore, resource use for concentrate production directly competes with the production of human food (Cassidy et al., 2013).

Almost in parallel with the increase in milk yield, there has been a distinct decrease in the length of the productive life of dairy cows, with cows reaching only 
2.5 to 3.3 parities before being culled (e.g., Hare et al., 2006). It is well known that milk yield increases in the first few lactations before it reaches a plateau between lactation 5 to 8 , after which it starts to decrease (Lubritz et al., 1989; Horn et al., 2012). Thus, a large part of the highly productive lifetime is systematically lost. This could be avoided with increased longevity, where there is also an environmental benefit given by the postponed replacement associated with proportionately lower numbers and, thus, emissions from replacement heifers that have to be reared (Bell et al., 2015). Promoting longevity would therefore dilute emissions from replacement. It is, however, still unresolved whether a longevity strategy is actually environmentally sound in terms of GHG emissions. The advantages mentioned could be counteracted by an increasing enteric $\mathrm{CH}_{4}$ emission with age, an aspect which has not yet been considered in life cycle analyses. Although no systematic study of such age effects exists, some controversial evidence exists. Ramírez-Restrepo et al. (2015) found no difference between $<1$-yr-old heifers and $>6$-yr-old cows in $\mathrm{CH}_{4}$ yield per kilogram of DMI. By contrast, the evaluation by Zeitz et al. (2012) across several experiments indicated an almost linear increase in $\mathrm{CH}_{4}$ yield per kilogram of DMI when opposing weaned, fattened calves to adult cows fed diets with similar concentrate proportions. Studies in sheep (Knight et al., 2008a) and red deer (Swainson et al., 2007) also reported greater $\mathrm{CH}_{4}$ yields per kilogram of DMI in mature animals compared with young animals. To the contrary, Knight et al. (2008b) found a greater $\mathrm{CH}_{4}$ yield per kilogram of DMI in 12- to 16-wk-old calves compared with 2 adult cows fed the same low-quality feed. None of these studies compared adult animals of different ages.

A high feed conversion and milk production efficiency is the key for economically viable production systems and, given that this can be accomplished with the same feeds, is important also from a world nutrition point of view (Connor, 2015). Cows with higher daily milk yield need relatively less feed (nutrients) for maintenance, and thus are particularly efficient in transforming nutrients into milk in the short term. But even at the same milk yield and BW, animal-to-animal variation in feed intake exists. Various methods of defining efficiency in dairy cows have been introduced (Coleman et al., 2010; Berry and Crowley, 2013; Connor, 2015). They range from ratio traits such as gross feed conversion efficiency (SCM or ECM per unit of feed intake) and milk production per unit of BW, to profitability-focused measures such as income over feed costs, and to residual feed intake (RFI) or residual solids production. The RFI is calculated as the difference between actual feed (or energy) intake of an animal and its predicted feed (energy) requirements (Hegarty et al., 2007). Numerous physiological processes have been related to feed-efficient animals, but the biological basis is not yet fully understood (Herd and Arthur, 2009).

Differences in feed intake were also found to explain a considerable share of the phenotypic and genotypic variance found in $\mathrm{CH}_{4}$ emission of sheep (Pinares-Patiño et al., 2013). Additionally, ruminal $\mathrm{CH}_{4}$ represents a loss of energy for the animal. Therefore, low- $\mathrm{CH}_{4}$ cows likely need less feed per kilogram of milk and would be potentially more feed-efficient. Consistent with this, Nkrumah et al. (2006) and Hegarty et al. (2007) found a low $\mathrm{CH}_{4}$ production in low-RFI beef cattle. Therefore, improving feed efficiency is a promising indirect approach for minimizing $\mathrm{CH}_{4}$ emission intensity and seems to be also directly related to $\mathrm{CH}_{4}$ emissions (Basarab et al., 2013). Evidence also exists that divergence in feed efficiency is retained from the calf stage to the lactating stage (Macdonald et al., 2014). However, information on age-related changes in feed efficiency in literature is scarce. Some of the processes affecting feed efficiency, such as feeding behavior (Dado and Allen, 1994; Maekawa et al., 2002) and fiber digestibility (Graham, 1980), might be influenced by senescence, but the extent to which such developments add up to efficiency changes with age is unclear.

The objective of the current study was to determine $\mathrm{CH}_{4}$ emissions and efficiency of dairy cows continuously across a large age range. With this approach, it was investigated whether (1) an increase in $\mathrm{CH}_{4}$ production with age in dairy cattle occurs and (2) whether this happens at a concomitant decrease in feed efficiency. It was further studied whether the age-dependent responses depend on diet type. Therefore, the age effects on $\mathrm{CH}_{4}$ emission were tested with cows fed 2 different diets, either with or without concentrate supplementation. Such feeding strategies could also part of highperformance versus longevity strategies. As enteric $\mathrm{CH}_{4}$ is linked to digestion characteristics (Okine et al., 1989; Pinares-Patiño et al., 2007; Goopy et al., 2014), the findings were related to additional data on intake and digestion available from the experimental animals (described in detail in Grandl et al., 2016).

\section{MATERIALS AND METHODS}

\section{Animals and Feeding}

The experiment was approved by the veterinary office of the Swiss canton of Zurich (149/2013). The experiment was carried out from October 2013 to February 2014. More details on the animals and the experimental procedures are given in Grandl et al. (2016).

The experimental animals were selected from 2 Brown Swiss herds kept at the Agricultural Education 
and Advisory Centre Plantahof (Landquart, Switzerland). These herds have been managed under different feeding regimens since 2003. In one feeding regimen, no concentrate was given (0-CONC). The diet in the other feeding regimen was designed to achieve a high milk yield with moderate amounts of concentrate (up to $5 \mathrm{~kg} / \mathrm{d}$ ). This reflects a diet type largely representative for conventional feeding of higher-yielding dairy cows and is therefore referred to as control feeding regimen (CTRL). Both herds received forage of high quality. The heifers of both feeding regimens were kept together and fed a forage-only diet. After the first parturition, the heifers were allocated to the feeding regimen in which they had been born.

For the experiment, $2 \times 15$ lactating dairy cows and 12 nonlactating heifers were selected from the 2 feeding regimens with the goal to achieve the widest possible age spectrum (199-3,638 d of age). There were 3 and 4 primiparous cows in 0-CONC and CTRL, respectively. The experiment was conducted in 7 subsequent runs with 6 animals each. On the first day of the experimental period, the animals were transported in pairs to the respiration chambers of Agrovet-Strickhof (Eschikon-Lindau, Switzerland), where they stayed for $3 \mathrm{~d}$. Afterward, the animals returned to Plantahof and the next pair was moved to the chambers. After the third pair had completed this cycle, an 8-d sampling period started, during which various traits describing feed intake, feeding behavior, and digestion were determined for all 6 animals. In that period, the cows were kept in the same tiestall barn as their herd mates. The cows were tethered the entire time.

For the lactating cows, the 0-CONC diet consisted of hay (ad libitum), corn silage $(22 \mathrm{~kg} / \mathrm{d}$ as fed), and grass pellets $(5 \mathrm{~kg} / \mathrm{d}$ as fed). Cows from the CTRL feeding regimen received the same forages, but more corn silage and less grass pellets (27 and $3 \mathrm{~kg} / \mathrm{d}$ as fed, respectively) plus an additional $5 \mathrm{~kg} / \mathrm{d}$ (as fed) of concentrate. The heifers ( 7 animals from 0-CONC, 5 from CTRL) received only hay, with ad libitum access during the experiment. The hay was taken from the same batches as that for the cows. As the lactating cows already received the winter diet serving as experimental diet, no adaptation was needed. The heifers were accustomed to the hay for $10 \mathrm{~d}$. To minimize differences in the chambers and in the tiestall, all diet components except corn silage were transported with the animals when they were moved to the respiration chambers.

\section{Animal Handling, Measurements, and Sampling}

In the chambers and in the tiestall, feeding was performed from 0300 to $0800 \mathrm{~h}$ and from 1415 to $1800 \mathrm{~h}$.
During each of these periods, hay was provided in portions of 1 or $2 \mathrm{~kg}$ (as fed), whereas corn silage was provided once. Grass pellets and concentrate were given in 2 and 4 portions per period, respectively (for details see Grandl et al., 2016). To avoid frequent entering of the chamber, some feeding events were combined with other activities, such as milking. Leftovers were removed and amounts were recorded before each new feeding period. The animals had always free access to water. The cows were milked shortly after the feeding periods started.

Samples of hay and corn silage were taken once per run. Samples of the grass pellets and the 2 concentrates, originating from the same batches, were collected twice in total. Subsamples of individual leftovers were dried at $60^{\circ} \mathrm{C}$ to constant weight for determination of DM. Standard procedures (AOAC International, 1995) were used for analysis of proximate contents (DM, OM, NDF; Grandl et al., 2016) in feed. In addition, gross energy contents were determined by bomb calorimetry (Calorimeter C7000 with Cooler C7002, IKA-Werke GmbH \& Co. KG, Staufen, Germany).

Body weight was measured on the first day of the 8-d collection period on a pallet scale. Milk yield was recorded at each milking by weighing of the milking bucket or using a mechanical milk meter (Tru-Test Limited, Auckland, New Zealand). Compositional analyses were performed on a MilkoScan FT6000 (Foss, Hillerød, Denmark) from Bronopol-conserved samples collected at every milking. Energy-corrected milk yield was calculated according to Agroscope (2015) as:

$$
\begin{gathered}
\text { ECM }(\mathrm{kg})=\text { milk }(\mathrm{kg}) \times[0.38 \times \text { fat }(\%) \\
+0.24 \times \text { protein }(\%)+0.17 \times \text { lactose }(\%)] / 3.14
\end{gathered}
$$

\section{Measurement of Methane Production}

All animals stayed for $3 \mathrm{~d}$ in open-circuit respiration chambers (described by Buehler and Wanner, 2014) at Agrovet-Strickhof. Data from the last $2 \mathrm{~d}(2 \times 24 \mathrm{~h})$ were used for evaluation. The 2 chambers used for cows and larger heifers had volumes of $19.3 \mathrm{~m}^{3}$ each. The calves were put into a chamber with $8.3 \mathrm{~m}^{3}$ of volume. The chambers were accessed by staff through airlocks to minimize the effects on gaseous exchange. They were air-conditioned to maintain a temperature of $18^{\circ} \mathrm{C}$ and a relative humidity of $55 \%$ at an air pressure of $-60 \mathrm{~Pa}$. Airflows were set to 700 and $250 \mathrm{~L} / \mathrm{min}$ in the larger and the smaller chambers, respectively (Promethion FG-1000 and FG-250 flow generators, Sable Systems Europe GmbH, Berlin, Germany). Concentrations of $\mathrm{CH}_{4}$ and $\mathrm{CO}_{2}$ were analyzed with a gas analyzer (Promethion GA-4, Sable Systems). Calibrations of 
the gas analyzers were done automatically before each measurement using pure $\mathrm{N}_{2}(99.999 \%)$ and a mixed gas (0.5\% $\mathrm{CO}_{2}, 0.1 \% \mathrm{CH}_{4}$, in $\mathrm{N}_{2}$ as carrier). Recovery was tested before each experimental period by burning of propane gas. The mean recovery rate was $96.9 \%$. Individual $\mathrm{CH}_{4}$ amounts were calculated as the average of the $2 \mathrm{~d}$ of measurement.

\section{Calculations and Statistical Analysis}

The efficiency measures calculated in the present study were feed conversion efficiency (ECM yield related to DMI), milk production efficiency (ECM yield related to BW), and RFI (difference between observed DMI and predicted DMI). For the latter, the predicted DMI was calculated according to Gruber et al. (2004; equation 2), as their predictions were developed from cow data recorded in similar production systems across various diets, years and herds. The prediction equation considers animal factors (breed, lactation number and stage, BW, milk yield) and feed characteristics (amount of concentrate, forage composition, and quality). The detailed calculation is given in the Appendix. Efficiency measures were only calculated for cows as the focus was on efficiency of milk production. Methane yield was assessed by relating absolute $\mathrm{CH}_{4}$ amounts to DMI, digestible OM intake (dOMI), digestible NDF intake (dNDFI), and gross energy intake (GEI; $\mathrm{CH}_{4}$ conversion factor). The $\mathrm{CH}_{4}$ energy was calculated as $39.57 \mathrm{~kJ} / \mathrm{L}$ (Brouwer, 1965). Methane emission intensity was computed by relating $\mathrm{CH}_{4}$ to $\mathrm{ECM}$ and $\mathrm{BW}$; the latter as $\mathrm{CH}_{4}$ was found to scale with $\mathrm{BW}^{1.00}$ rather than $\mathrm{BW}^{0.75}$ (Franz et al., 2010). Intake and ECM yield data used for these calculations were derived from the stay in the 8-d period in the tiestall. This was preferred to using the data obtained in the chambers because digestibility data (taken from Grandl et al., 2016) used for calculating some of the $\mathrm{CH}_{4}$ traits were from the latter period, when DMI and ECM data likely were less variable than during the $2 \mathrm{~d}$ of measurement. The average data were very similar with 15 to 27 (digestibility period) and 14 to $27 \mathrm{~kg} / \mathrm{d}$ of DMI (chamber period) as well as 17 to $35 \mathrm{~kg}$ of ECM/d for both sites.

All statistical analyses were performed with the software R (R Core Team, 2015). Data were subjected to parametric regression analyses, with the best model for traits in cows being selected by screening all possible subsets of the following full model:

$$
\begin{gathered}
Y_{\mathrm{ijklmnop}}=\mu+\mathrm{FR}_{\mathrm{i}}+\beta_{\mathrm{j}} \mathrm{A}+\beta_{\mathrm{k}} \ln (\mathrm{A})_{\mathrm{j}} \\
+\beta_{\mathrm{l}}(\mathrm{A} \times \mathrm{FR})+\beta_{\mathrm{m}} \ln (\mathrm{BW})+\beta_{\mathrm{n}} \mathrm{ECM} \\
+\beta_{\mathrm{o}} \text { HayProp }+\varepsilon_{\mathrm{ijklmnop}},
\end{gathered}
$$

where $Y_{\mathrm{ijklmnop}}=$ individual observation of the respective trait; $\mu=$ overall mean; $\mathrm{FR}_{\mathrm{i}}=$ fixed effect of the feeding regimen $i ; \beta_{j \ldots o}=$ regression coefficients of the continuous fixed effects of age (A, linear and ln-transformed), of the interaction of age and feeding regimen $(\mathrm{A} \times \mathrm{FR})$, and of the covariates $\ln (\mathrm{BW}), \mathrm{ECM}$ yield, and hay as proportion of forage DMI (HayProp); and $\varepsilon_{\mathrm{ijklmnop}}=$ random residual. Including age both as linear and ln-transformed effect allowed modeling nonlinear relationships of the traits with age. To obtain adjusted effects of feeding regimen and age, BW and ECM yields of the cows were included as covariates. Hay as a proportion of forage intake (hay, corn silage, and grass pellets; on a DM basis) was an additional covariate to correct for potential individual preferences for hay versus the other forages (particularly corn silage). Body weight was included as an ln-transformed variable, as it is known that many digestion traits show a nonlinear relationship with BW (Müller et al., 2013). Out of all possible subsets of the full model, only models which included age (in any transformation) and feeding regimen were considered, and these were ranked according to the Akaike information criterion (Akaike, 1974), modified for small sample sizes (Symonds and Moussalli, 2011) using the package 'glmulti' (Calcagno, 2013). If the values of the information criterion ( $\boldsymbol{\Delta} \mathbf{A I C C})$ differed by less than 2 , models were considered to be equal, and the final model was then chosen following the parsimony rule as the one with the least number of coefficients (Symonds and Moussalli, 2011). Additionally, in nested models with $\triangle$ AICC of less than 2 , the significance of additional coefficients was tested with a likelihood-ratio test. For non-nested models with $\triangle$ AICC of less than 2 with the same number of coefficients, their coefficient of determination and the residual sum of squares were compared. All criteria matched the results of the $\triangle \mathrm{AICC}$ ranking and the parsimony rule as decision criterion almost perfectly, except for DMI, where BW, though not being significant $(P=0.125)$, was included in the model because greater BW is known to result in greater feed intake (e.g., Jensen et al., 2015).

For data of the nonlactating heifers, a separate regression model including feeding regimen and age as effects was applied, because age effects in heifers were presumed to be related to the growth and development of the juvenile animal. In contrast, age effects in mature cows were likely to be related to senescence. Furthermore, BW is naturally highly collinear with age in growing heifers, and the other covariates (ECM yield, hay proportion) used in the cow regressions were not applicable to the heifer data. The same diet was fed to heifers from both regimens. Thus, if significant feeding regimen differences existed in heifers, these would indi- 
cate genuine effects from the $10 \mathrm{yr}$ of selection within feeding regimen. However, as no significant feeding regimen effect ever existed in heifers, heifer data are presented across both feeding regimens. The WilcoxonMann-Whitney rank sum test was used to compare the medians of heifer and cow data.

Adjusted means for the feeding regimens (Table 1) were calculated with the R package 'effects' (Fox, 2003). The figures display measured individual data points, as well as regression lines and pointwise confidence bands for heifers and for cows, where the covariates (if in the model) were held constant at their median. If equivalent models (i.e., $\triangle \mathrm{AICC} \leq 2$ ) were identified, further regression lines were added to indicate model selection uncertainty. Model assumptions were verified by analysis of residuals, which were graphically analyzed for normality, independence, and homoscedasticity of the errors. Effects were considered as statistically significant at $P<0.05$ and as trends at $0.05 \leq P<0.10$.

\section{RESULTS}

\section{Performance and Efficiency Traits}

Cows differed $(P<0.05)$ in BW between feeding regimens, with the 0 -CONC cows being on average approximately $40 \mathrm{~kg}$ lighter than the CTRL cows (Table 1). No BW difference was found between feeding regimens in the heifers. As body measurements (height at withers, height at hips, heart girth, body length, body depth) did not differ between groups (data not shown), the greater $\mathrm{BW}$ of the CTRL cows indicates a better body condition (not measured as BCS). The BW of the cows increased $(P<0.01)$ with age. Energy-corrected milk yield was lower $(P<0.05)$ in the 0 -CONC cows compared with the CTRL cows (Table 1 ) and tended to increase $(P=0.06)$ with age (Figure $1 b)$. In heifers, BW increased with age.

The regression analysis (Table 2) showed a significant positive relationships of DMI with age. Uncorrected average DMI was greater in CTRL compared with $0-\mathrm{CONC}$ cows (22.0 and $20.5 \mathrm{~kg}$ of $\mathrm{DM} / \mathrm{d}$, respectively), but no difference between the feeding regimens was found in DMI when the covariates were included in the regression analysis (Table 1). In the heifers, a linear increase of DMI was found with increasing age (Figure 1c). However, when DMI was related to BW in the heifers, DMI tended to decrease in older heifers (Figure 1d).

When ECM yield was expressed per unit of BW, BW and ECM yield were excluded from the full regression model. No age or feeding regimen effects on milk production efficiency were observed (Figure 1e; Table 2). No age effects and no differences between feeding regimens in feed conversion efficiency (ECM/ DMI; Tables 1 and 2) were observed. By contrast, the

Table 1. Average intake, performance, and methane production of heifers and of cows from the control feeding regimen (CTRL) and the zero concentrate feeding regimen $(0-\mathrm{CONC})$, presented as arithmetic means for heifers ${ }^{1}$ and adjusted means and CI ${ }^{2}$ (in brackets) for cows

\begin{tabular}{|c|c|c|c|c|c|c|c|}
\hline \multirow{3}{*}{$\begin{array}{l}\text { Item } \\
\mathrm{BW}^{4}(\mathrm{~kg})\end{array}$} & \multicolumn{2}{|c|}{ Heifers $(\mathrm{n}=12)$} & \multicolumn{5}{|c|}{ Lactating cows ( $\mathrm{n}=15$ each) } \\
\hline & \multirow{2}{*}{$\begin{array}{l}\text { Mean } \\
401\end{array}$} & \multirow{2}{*}{$\frac{\mathrm{SE}}{29.0}$} & \multicolumn{2}{|c|}{ CTRL } & \multicolumn{2}{|c|}{$0-\mathrm{CONC}$} & \multirow{2}{*}{$\frac{P \text {-value }}{3}$} \\
\hline & & & 710 & {$[687-734]$} & 669 & {$[646-692]$} & \\
\hline ECM (kg/d) & - & - & 28.2 & {$[26.6-29.8]$} & 25.8 & {$[24.2-27.3]$} & 0.032 \\
\hline DMI $(\mathrm{kg} / \mathrm{d})$ & 8.05 & 0.452 & 21.5 & {$[20.7-22.2]$} & 21.3 & {$[20.5-22.1]$} & 0.793 \\
\hline DMI $(\mathrm{kg} / \mathrm{d}$ per $100 \mathrm{~kg}$ of BW) & 2.05 & 0.079 & 3.09 & {$[2.98-3.20]$} & 3.06 & {$[2.94-3.19]$} & 0.780 \\
\hline \multicolumn{8}{|l|}{ Efficiency } \\
\hline ECM per BW (kg/100 kg) & - & - & 4.03 & {$[3.79-4.26]$} & 4.00 & {$[3.76-4.26]$} & 0.860 \\
\hline ECM per DMI $(\mathrm{kg} / \mathrm{kg})$ & - & - & 1.30 & {$[1.23-1.36]$} & 1.26 & {$[1.20-1.32]$} & 0.426 \\
\hline Residual feed intake $^{5}(\mathrm{~kg} / \mathrm{d})$ & - & - & 0.24 & {$[-0.38-0.85]$} & 2.52 & {$[1.90-3.13]$} & $<0.001$ \\
\hline Methane production (g/d) & 179 & 16.2 & 468 & {$[427-509]$} & 508 & {$[473-543]$} & 0.086 \\
\hline \multicolumn{8}{|l|}{ Methane yield } \\
\hline $\mathrm{g} / \mathrm{kg}$ of DMI & 21.8 & 1.06 & 21.5 & {$[20.2-22.7]$} & 23.8 & {$[22.6-24.9]$} & 0.002 \\
\hline $\mathrm{g} / \mathrm{kg}$ of digestible OM intake & 35.5 & 1.76 & 33.5 & {$[31.0-35.9]$} & 38.2 & {$[36.0-40.4]$} & 0.001 \\
\hline $\mathrm{g} / \mathrm{kg}$ of digestible NDF intake & 64.2 & 3.47 & 103.6 & {$[96.2-111.1]$} & 96.9 & {$[89.7-104.1]$} & 0.188 \\
\hline$\%$ of gross energy & 6.73 & 0.324 & 6.42 & {$[6.04-6.80]$} & 7.26 & {$[6.92-7.60]$} & $<0.001$ \\
\hline \multicolumn{8}{|l|}{ Methane emission intensity } \\
\hline $\mathrm{g} / \mathrm{kg}$ of $\mathrm{ECM}$ & - & - & 17.0 & {$[15.6-18.5]$} & 18.4 & {$[17.2-19.7]$} & 0.089 \\
\hline $\mathrm{g} / 100 \mathrm{~kg}$ of BW & 44.3 & 2.24 & 65.3 & {$[59.4-71.3]$} & 75.0 & {$[69.8-80.1]$} & 0.008 \\
\hline
\end{tabular}

${ }^{1}$ Heifers from both feeding regimens are combined in the table, as they were fed the same diet and no differences between feeding regimens were found.

${ }^{2}$ Adjusted means (fitted values for feeding regimen levels keeping age, BW, ECM yield, and hay proportion at their median) and 95\% CI.

${ }^{3} P$-value of regression coefficient of feeding regimen from analysis of cow data.

${ }^{4}$ Data as given in Grandl et al. (2016).

${ }^{5}$ Difference between observed DMI and estimated DMI according to Gruber et al. (2004). 
a

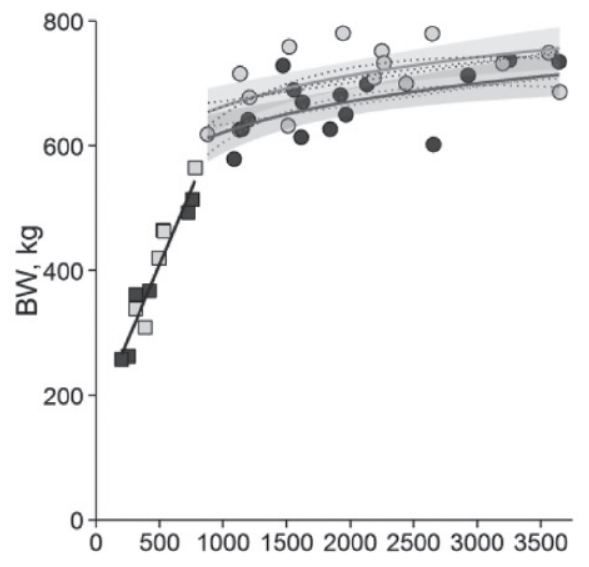

d

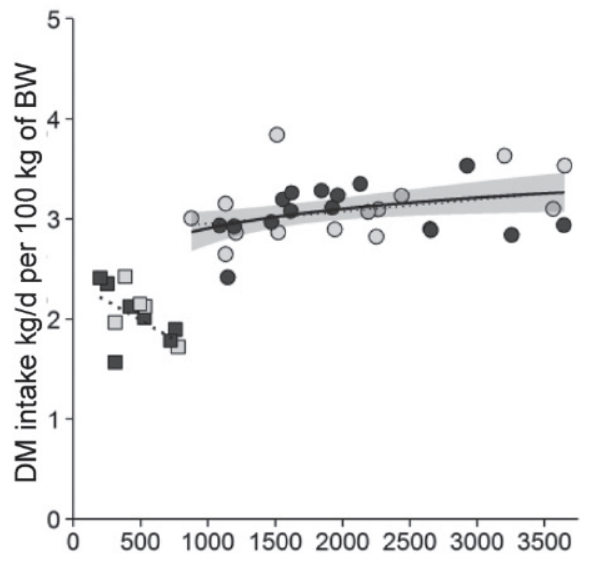

$\mathrm{f}$

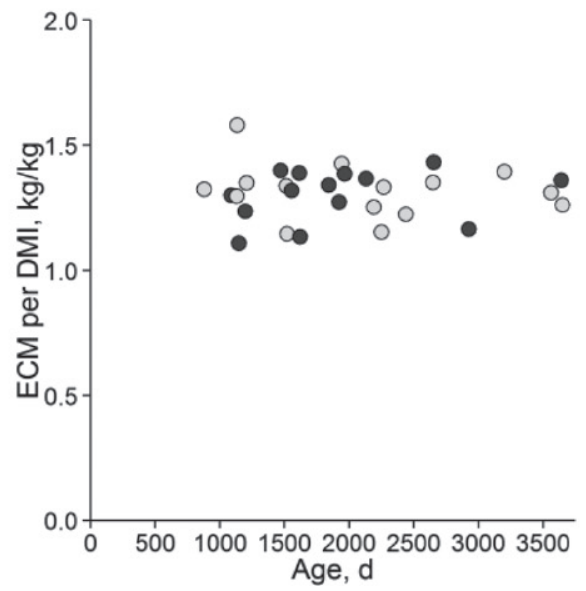

b

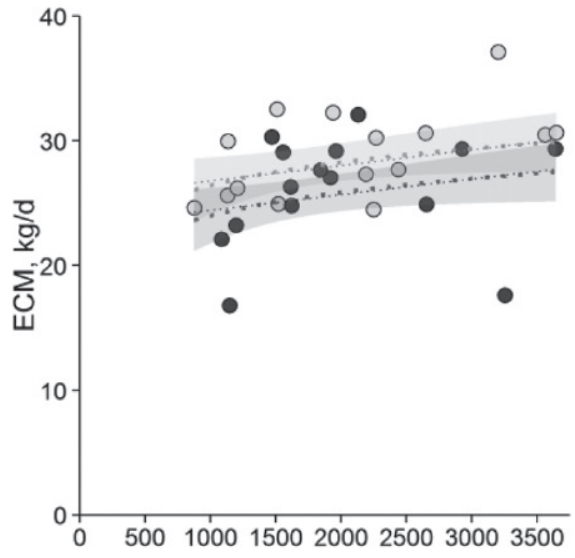

$\mathrm{e}$

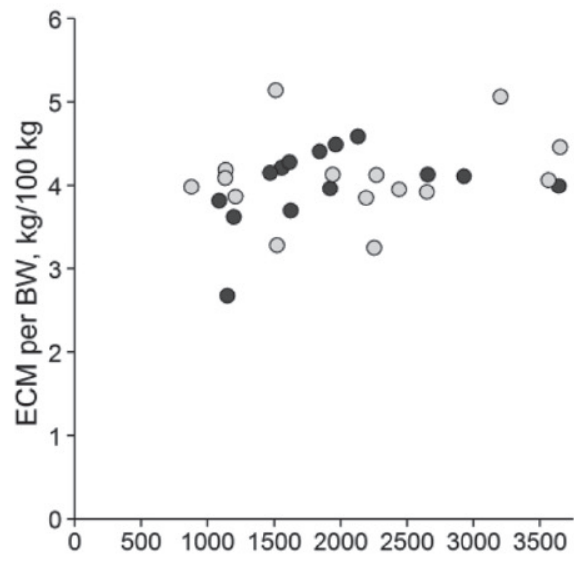

g

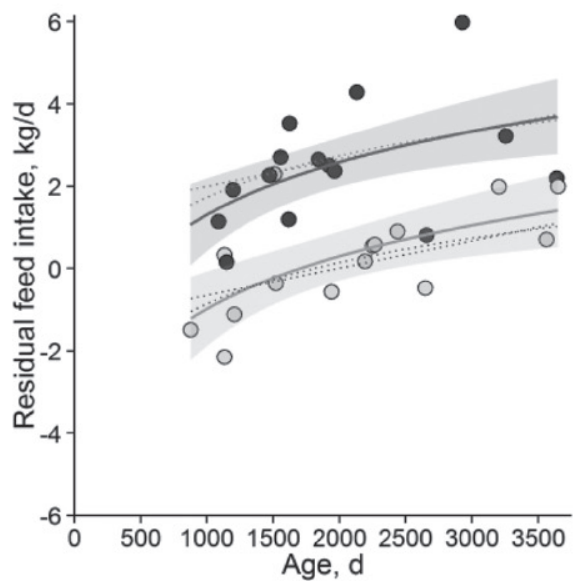

C

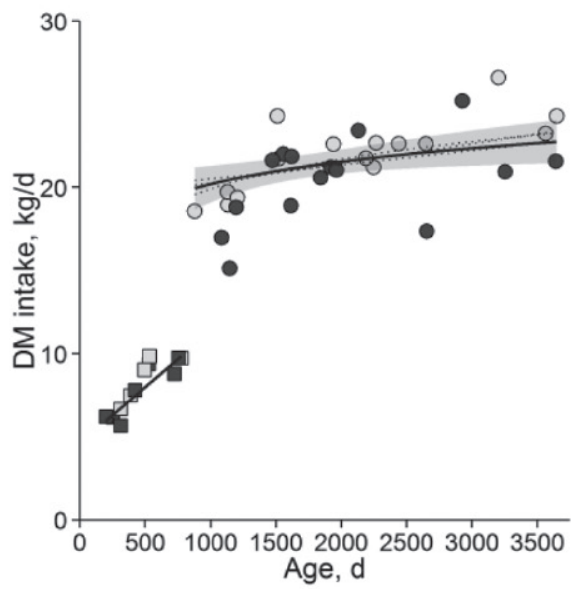

Figure 1. Observed values for cows and heifers and prediction lines for regression fits for heifers and cows (varying age but keeping BW, ECM yield, and hay proportion in forage to the respective median) for performance and efficiency traits. Symbol and line shading indicate values and prediction lines for control (CTRL; open, light gray) and zero concentrate (0-CONC; solid, dark gray) animals. Predictions were illustrated by solid lines if the regression coefficients for age and feeding regimen were significant at $P<0.05$. Dotted lines were drawn for 0.05 $\leq P<0.10$ for age. Only one prediction line was drawn in case of $P \geq 0.10$ for feeding regimen. For cow regressions, shaded areas represent $95 \%$ confidence bands, and thin dotted lines represent prediction lines for regression fits of regression models within a difference $<2$ in Akaike information criterion value between the best and the respective model. The medians of heifer and cow data were significantly $(P<0.001)$ different in the traits described in a, c, and $\mathrm{d}$. 
Table 2. Regression coefficients for cows and their statistical significance

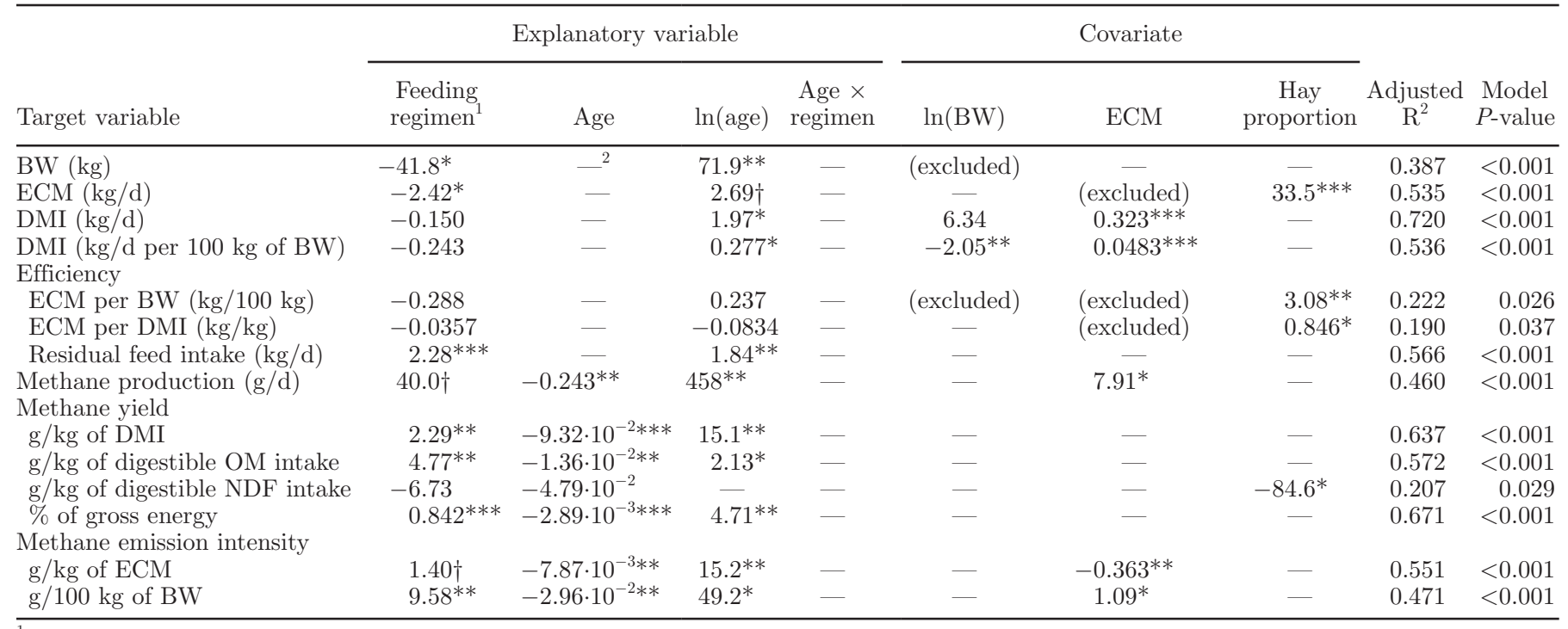

${ }^{1}$ Reference level is the control feeding regimen.

${ }^{2}$ Variable not included in the final regression model after the variable selection procedure.

*** $P<0.001,{ }^{* *} P<0.01,{ }^{*} P<0.05 ; \dagger P<0.10$.

RFI, calculated as the difference between observed and predicted DMI, was greater $(P<0.001)$ in the 0 -CONC compared with the CTRL cows. The RFI increased $(P<0.01)$ with age independent of feeding regimen (Table 2 and Figure 1g), indicating a decrease in feed efficiency with age. No significant interaction between feeding regimen and age was found in heifers and cows in the traits describing performance and efficiency.

\section{Methane Emissions}

Cows of the $0-\mathrm{CONC}$ regimen, compared with cows from the CTRL, produced more $(P<0.01) \mathrm{CH}_{4}$ per kilogram of DMI, dOMI, and GEI (Table 1), and absolute $\mathrm{CH}_{4}$ production tended $(P=0.09)$ to be greater in 0 -CONC cows. We noted no differences between feeding regimens when $\mathrm{CH}_{4}$ was related to dNDFI. Methane emission intensity was also higher $(P<0.01)$ in 0-CONC compared with CTRL cows when expressed as $\mathrm{CH}_{4}$ per unit of $\mathrm{BW}$, and tended $(P=0.09)$ to be higher for $\mathrm{CH}_{4}$ per kilogram of ECM (Table 1). The $\mathrm{CH}_{4}$ emission level found in the heifers was in the same range of that of the $0-\mathrm{CONC}$ cows when related to DMI, dOMI, and GEI. Concerning $\mathrm{CH}_{4}$ per dNDFI and $\mathrm{CH}_{4}$ per $\mathrm{BW}$, heifers expressed slightly lower $(P$ $<0.001$ ) emissions compared with cows. We found no significant difference between feeding regimens in any of the $\mathrm{CH}_{4}$ traits measured in the heifers.

All $\mathrm{CH}_{4}$ traits, except $\mathrm{CH}_{4}$ per kilogram of dNDFI, were related $(P<0.05)$ to age in the cows (Table 2;
Figure 2a-g). Methane per unit of dNDFI was only poorly predictable with the explanatory variables given (adjusted $\mathrm{R}^{2}=0.21$ ). A curvilinear relationship with age was evident for all other $\mathrm{CH}_{4}$ traits (Figure 2a-g). Emissions were highest in multiparous cows aged 4 to 6.5 yr (i.e., in cows in lactation 2-3). Both primiparous cows and older multiparous cows (6.5 to $10 \mathrm{yr}$ and lactation $5-7$, respectively) were slightly lower in $\mathrm{CH}_{4}$ production. In heifers, an increasing $(P<0.05) \mathrm{CH}_{4}$ production with age was identified for all $\mathrm{CH}_{4}$ traits apart from $\mathrm{CH}_{4}$ per kilogram of dOMI $(P=0.10)$ and $\mathrm{CH}_{4}$ per BW $(P=0.36$; Figure 2a-g). The latter confirms the inseparability of age and BW effects in the heifers. No significant interaction was noted between feeding regimen and age in heifers or cows.

\section{DISCUSSION}

In the present study, a population of heifers and lactating cows with age ranging from 0.5 to $10 \mathrm{yr}$ was observed. Any age-related effects could be relevant for an environmental assessment of strategies focusing on longevity and limited use of concentrate. To study the latter, cows were selected from herds adapted to 2 distinct feeding strategies for more than $10 \mathrm{yr}$. However, in none of the traits described were significant interactions of age and feeding regimen found. Obviously, efficiency and $\mathrm{CH}_{4}$ emission were not developing differently with age under different diet types and long-term feeding regimens. However, more contrasting feeding 
a

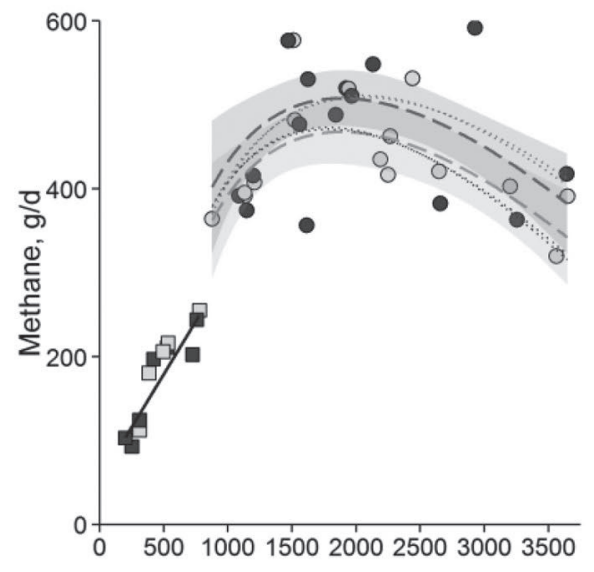

d

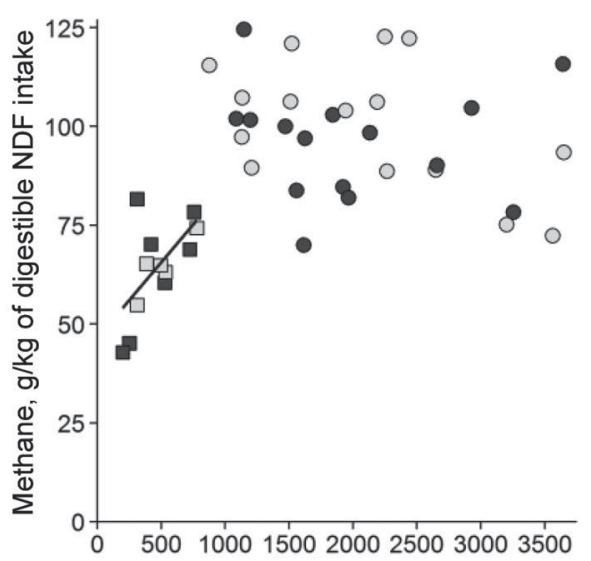

f

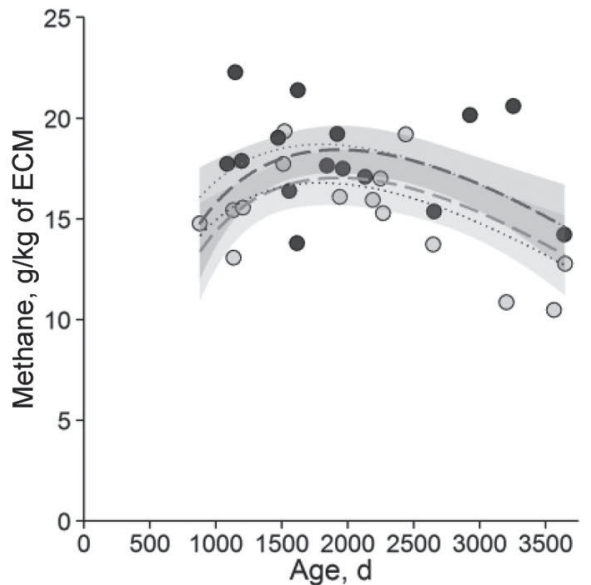

b

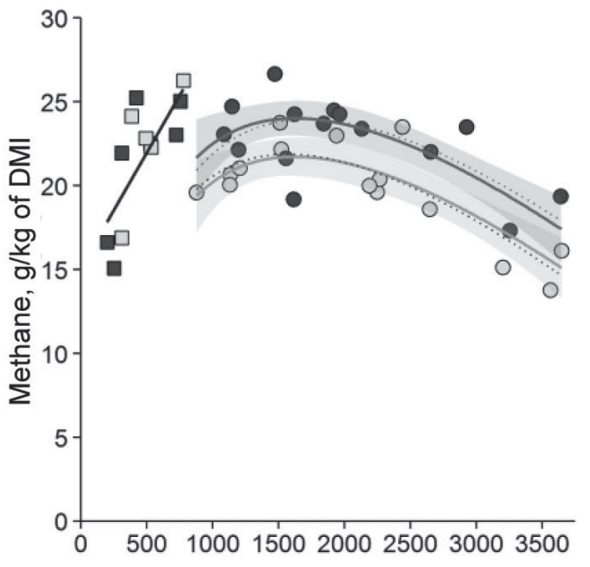

e

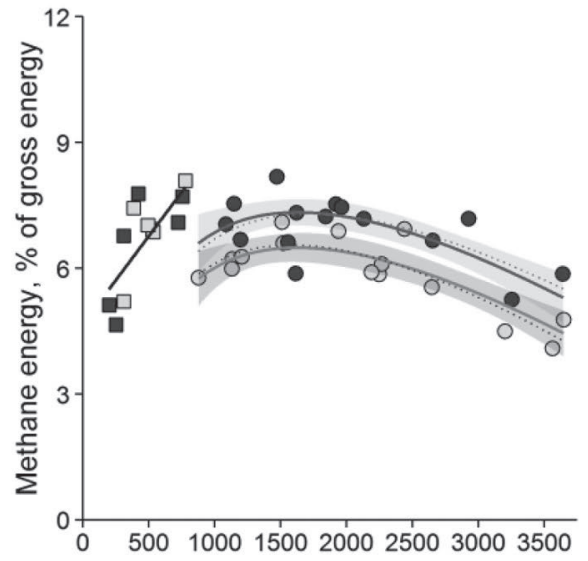

g

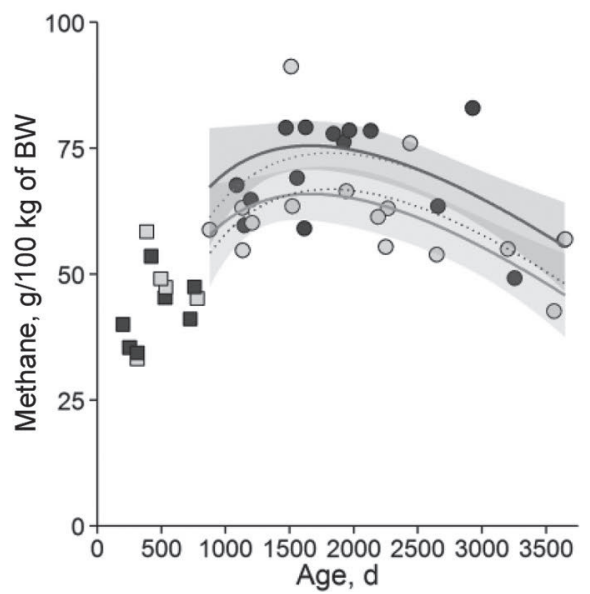

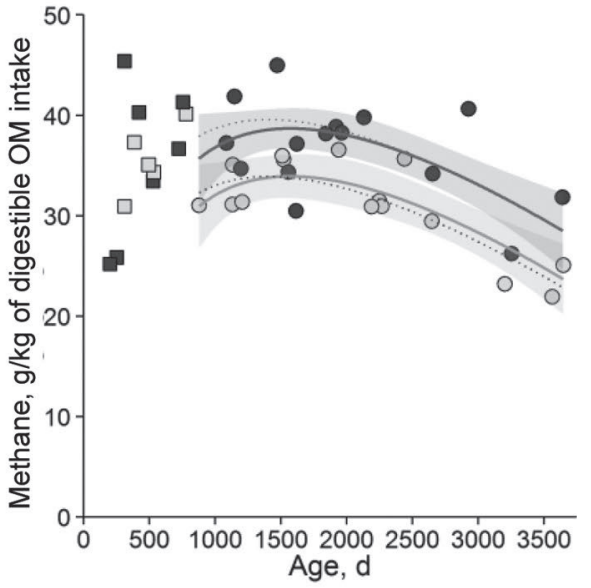

Figure 2. Observed values for cows and heifers and prediction lines for regression fits for heifers and cows (varying age but keeping BW, ECM yield, and hay proportion in forage to the respective median) for methane traits. Symbol and line shading indicate values and prediction lines for control (CTRL; open, light gray) and zero concentrate (0-CONC; solid, dark gray) animals. Predictions were illustrated by solid lines if the regression coefficients for age and feeding regimen were significant at $P<0.05$. Dashed lines were drawn for $0.05 \leq P<0.10$ for feeding regimen. For cow regressions, shaded areas represent $95 \%$ confidence bands, and thin dotted lines represent prediction lines for regression fits of regression models within a difference $<2$ in Akaike information criterion value between the best and the respective model. The medians of heifer and cow data were significantly $(P<0.001)$ different in the traits described in a, d, and $g$. 
regimens than those investigated in the present study might still reveal that differences in adaptation with age are possible.

With the present animal population it cannot be ruled out that the observed development with age was partly the result of an animal selection effect. The older cows in the study have probably been deliberately excluded from culling at several selection decisions over time. Thus, a bias in the older cows taken from a preselected group of animals with certain characteristics might exist.

In Grandl et al. (2016), several variables of intake and digestion are described for the same animals, which are potential causes for variations in $\mathrm{CH}_{4}$ production (Moss et al., 2000; Goopy et al., 2014). These are used in the course of the following discussion.

\section{Age Effects on Efficiency Traits}

In the performance traits, namely BW, ECM yield, and DMI, some age-related changes were noted. Dry matter intake and also ECM yield, by tendency, increased with age, but the initial increase from primiparous cows to cows with few lactations seemed to level out in older cows. Milk production efficiency (ECM/BW) and feed conversion efficiency (ECM/DMI) showed no changes with age, whereas RFI increased with age. Herd and Arthur (2009) explained individual differences in RFI in beef cattle by physiological processes, such as feed intake, digestion, metabolism, and thermoregulation. Among them, feeding behavior was also identified to influence energy efficiency. Accordingly, Basarab et al. (2013) found positive phenotypic correlations between RFI and chewing activity, indicating that energyefficient animals spend less time feeding compared with less efficient animals (Connor et al., 2013). However, the observed eating times per kilogram of DMI (Grandl et al., 2016), which were lowest in the oldest cows, do not confirm the trend toward a decreasing efficiency with age as found for RFI in the present study. Another factor explaining variation in RFI according to Herd and Arthur (2009) are differences in digestibility. Richardson and Herd (2004) found a negative correlation between digestibility and RFI. In the present experiment (Grandl et al., 2016), the apparent digestibility of OM remained rather unchanged with age, which did not coincide with RFI. Only NDF digestibility was lower in older cows compared with the middleaged cows. Further, differences in energy expenditure for thermoregulation and activity were mentioned by Herd and Arthur (2009) as contributing to variation in RFI. However, relevant differences in variables related to these physiological complexes were very unlikely to occur in the experimental setup. Therefore, possible reasons for the increase in RFI were likely of a metabolic nature. Changes in body composition with age (e.g., different fat to lean tissue ratio in cows of different age) could result in different maintenance requirements, which are not accounted for in the prediction of DMI. Another aspect might be relevant with respect to RFI, as a certain overestimation of the age effect might have occurred, especially in the transition from primiparous to multiparous cows due to the method used for predicting DMI in the RFI calculation. Gruber et al. (2004) considered effects of lactation number for cows in their first, second, and third lactation in their DMI prediction. This adjustment might not have fully matched the present animal population due to their comparably high age at first calving (approximately 35 mo with 1 exception), and thus the calculated increase in RFI with age might be biased. Furthermore, the efficiency measures calculated in the present study are only based on the 8-d experimental period and are therefore susceptible to short-term variation in performance or in body mobilization during the experimental phase (Berry and Crowley, 2013).

\section{Age Effects on Methane Emissions}

A previous compilation of results from growing versus adult cattle indicated that an increase in $\mathrm{CH}_{4}$ yield from young to adult cattle might occur, but it was not possible to clarify whether this development continues with age in adult dairy cows (Zeitz et al., 2012). In the growing heifers of the present study, an increase in absolute $\mathrm{CH}_{4}$ emission with age was noted, which was expected from increasing body size and DMI. However, even when $\mathrm{CH}_{4}$ yield was calculated, a trend in the growing heifers toward increasing emissions with age remained. This is consistent with the observation that the digestive system is still in development in young ruminants (Guilloteau et al., 2009). The hay-only fed heifers showed $\mathrm{CH}_{4}$ yields (per DMI and GEI) closer to those of the 0-CONC cows than to the CTRL group, which is plausible because both received forage-only diets. Methane yield was, however, lower in heifers than in cows when related to dNDFI. Age effects on $\mathrm{CH}_{4}$ emissions have been investigated in growing ruminants before (e.g., sheep: Graham, 1980; cattle: Molano et al., 2006 and Jiao et al., 2014; deer: Swainson et al. 2007). However, in cases where changes with age were found, no consistent explanations on the mechanisms were provided, either because the factors of influence were too complex or the studies were limited to comparisons of young versus mature animals. Ramírez-Restrepo et al. (2015) recently described the results of a con- 
trolled experiment comparing growing and adult dairy cattle. The authors did not find a difference in $\mathrm{CH}_{4}$ yield (about 24 to $25 \mathrm{~g}$ of $\mathrm{CH}_{4} / \mathrm{kg}$ of DMI) between female heifers observed from 110 to $480 \mathrm{~d}$ of age and cows observed from 2,500 to 2,800 d of age. Despite the difference in diets, no major difference in $\mathrm{CH}_{4}$ per DMI was noted in the present study between the heifers and the cows that were similarly old (about lactation 4-5) as the cows in the study by Ramírez-Restrepo et al. (2015). Still the lack of an age effect in the study by Ramírez-Restrepo et al. (2015) was puzzling, as in their study all animals were fed on the same batches of forage and received no concentrate. However, the DMI of the cows in their study was only 6 to $7 \mathrm{~kg}$, suggesting that they were nonlactating.

In the lactating cows of the present study, a curvilinear relationship between age and $\mathrm{CH}_{4}$ production was found. Emissions of $\mathrm{CH}_{4}$ reached a peak in lactation 2 to 3. Older cows from around $6.5 \mathrm{yr}$ of age onwards had lower levels, both in terms of absolute emissions and when expressed as $\mathrm{CH}_{4}$ yields and emission intensities. As growth of cows was probably completed before the emission peak (Bazzoli et al., 2014), the age-related changes in $\mathrm{CH}_{4}$ production were probably mostly due to animal characteristics related to animal feeding behavior and digestion efficiency. Methane production in ruminants is in essence the result of the availability of fermentable substances, which are degraded in the rumen over a certain amount of time. It therefore seems straightforward to assume that feed intake, retention time of feed in the digestive tract and digestibility of nutrients - particularly of fiber - could have influenced $\mathrm{CH}_{4}$ production (Moss et al., 2000) in the present study. These traits themselves are at least partially dependent on other factors, such as mechanical comminution of feeds (Ulyatt et al., 1986) or the suitability of the conditions for the rumen microbes (Allen and Mertens, 1988).

The animal model applied in the present study was suitable to discriminate diet-related effects on $\mathrm{CH}_{4}$, as can be seen from the results obtained with the 2 feeding regimens. Within feeding regimen, feed-dependent effects were controlled for by including the proportion of hay in the ingested forage as a covariate. A low hay proportion would have favored a lower $\mathrm{CH}_{4}$ emission due to a shift from fiber to starch. However, this covariate was not significant in the $\mathrm{CH}_{4}$ traits except for $\mathrm{CH}_{4}$ per dNDFI. Overall DMI and NDF intake increased markedly from primiparous to cows with few parities, but remained more or less constant from then onwards, which therefore does not explain the decline in absolute $\mathrm{CH}_{4}$ emission with higher age. There are indications that low feed efficiency per high RFI and high $\mathrm{CH}_{4}$ emission are directly related (Hegarty et al., 2007; Basarab et al., 2013); thus, the trend toward a slightly lower feed efficiency in older cows should rather have been associated with increased $\mathrm{CH}_{4}$ emissions. Another explanation would be changes in digestive physiology with age. From the experiment, data on several digestion characteristics were available (Grandl et al., 2016). An increasing relative feed intake is expected to result in a shorter ruminal retention time of the feed (e.g., Allen and Mertens, 1988). However, the greater feed intake in the older cows of the present study did not result in shorter mean retention times. These cows therefore seemed to have a greater capacity of the digestive tract, which allowed them to ingest more feed and also to retain it longer. Based on these observations, the observed reduction in $\mathrm{CH}_{4}$ production was unexpected, as the passage rate of feed in the digestive tract is presumed to be negatively correlated with $\mathrm{CH}_{4}$ production (Okine et al., 1989). The only change which likely explained the observed development of $\mathrm{CH}_{4}$ emissions is the concomitant curvilinear relationship with age in fiber digestibility (lower in young and old cows), which largely levelled out age effects on $\mathrm{CH}_{4}$ when related to dNDFI. Similar patterns of variation were found in rumination traits (Grandl et al., 2016). The stage of age of the greatest chewing efficiency was apparently that of the medium-aged cows, which resulted in fiber degradation and thus $\mathrm{CH}_{4}$ formation being at its maximum in these cows.

\section{Effects of Feeding Regimen on Efficiency and Methane Emissions Traits}

Cows of the 2 feeding regimens did not clearly differ in DMI, which seems contradictory to the lower BW and ECM yield of the 0-CONC animals compared with the CTRL animals. However, cows are able to compensate for the lower energy density of the forage-only diet compared with the CTRL diet by an increased forage consumption (Leiber et al., 2015). This might also explain the differences found in RFI. However, the 0 -CONC diet is likely an extreme in the data set used to derive the prediction equation for DMI. Thus, the RFI could be slightly biased by the calculation of the predicted DMI. Indeed, in ECM yield per unit of BW and per unit of DMI, we found no feeding regimen difference. The latter reflects the comparably high quality of the forage-only diet.

Compared with the CTRL cows, $\mathrm{CH}_{4}$ emissions were higher in the 0-CONC cows. This was apparent for both $\mathrm{CH}_{4}$ yield and emission intensity in the order of an 8 to $15 \%$ difference. The $\mathrm{CH}_{4}$ conversion factor $\left(\mathrm{CH}_{4}\right.$ energy, percent of gross energy) was found to be slight- 
ly greater with the 0-CONC cows and slightly smaller with the CTRL cows compared with the default value of $6.5 \%$ proposed by IPCC (2006). The average of both herds was quite close to this value. The only exception where feeding regimen differences were absent was $\mathrm{CH}_{4}$ per dNDFI. Increasing the concentrate proportion in ruminant diets was shown to often cause a reduction in enteric $\mathrm{CH}_{4}$ (Beauchemin et al., 2008; Hristov et al., 2013a). From a fermentation point of view, the differences observed between feeding regimens are mainly related to shifts in carbohydrate profile (fiber vs. nonfiber carbohydrates; Knapp et al., 2014) and therefore acetate and propionate production liberating different amounts of $\mathrm{H}_{2}$ (Janssen, 2010). As the CTRL diet contained only about $20 \%$ concentrate in DM, the limited mitigating effect of this concentrate proportion could be expected (e.g., Hindrichsen et al., 2006; Aguerre et al., 2011). Additionally, different dietary characteristics may also cause changes in mechanical and chemical feed degradation as a result of changed rumination activity or ruminal retention times. However, this was obviously not the case in the animals of the present study (Grandl et al., 2016). The partial replacement of concentrate by grass pellets could also have lowered the feeding regimen effect. Such processed forages are known to express a lower $\mathrm{CH}_{4}$ yield (Hironaka et al., 1996; Benchaar et al., 2001) due to decreased fiber degradation and enhanced feed intake. The general feeding regimen treatment had no significant influence on $\mathrm{CH}_{4}$ emissions of the heifers fed hay only. Therefore, more than $10 \mathrm{yr}$ of selecting replacement animals exclusively within feeding regimen did not yet result in differences, for example, in the capacity of the rumen.

\section{CONCLUSIONS}

The main prediction tested in the present study was that absolute $\mathrm{CH}_{4}$ emission, $\mathrm{CH}_{4}$ yield, and intensity of $\mathrm{CH}_{4}$ would increase with age. An increase was indeed found during the first few lactations, whereas it was reversed in older cows. This decline seems to result from a reduction in fiber digestibility at unchanged OM digestibility. The reasons for that might include changes in intake and chewing efficiency or anatomic changes in the digestive system in the lifetime of dairy cows, which are not related to differences in animal size (BW) and ECM yields. Finally, the age effects were apparent irrespective of the feeding regimen. Even when considering the uncertainties of unknown mechanisms of changes in $\mathrm{CH}_{4}$ emissions, the results made it evident that no increase in $\mathrm{CH}_{4}$ emission with age occurred in older cows. On the contrary, the calculated efficiency measures showed no clear developments with age. The present results provide arguments supporting intentions to increase the length of the productive life in dairy cows and are important for the implementation of a longevity strategy in milk production systems. These considerations do not include the additional benefit generated from the increasingly lower share of the environmental and economic costs for the replacement of cows. Comprehensive life cycle analyses will have to show the relative importance of these emission changes in relation to replacement costs, and to provide arguments for the evaluation of the ideal age which should be achieved with all cows which do not have to be culled for clinical reasons.

\section{ACKNOWLEDGMENTS}

We thank A. Accola, D. Balestra, C. Brandenburger, K. Freuler, J. Jenewein, P. Küchler from Plantahof, M. Hunziker, H. Renfer, S. Rinderknecht, and U. Voegeli from Agrovet-Strickhof, S. Marquardt, R. Messikommer from ETH Zurich, and the laboratory team at ETH Zurich (C. Kunz, M. Mergani, P. Stirnemann, E. Wenk). Special thanks go to M. Kalisch (ETH Zurich) and M. Dolezal (University of Veterinary Medicine, Vienna) for their assistance in the statistical analysis. The authors are grateful to the Mercator Research Program of the ETH Zurich World Food System Center for supporting this project.

\section{REFERENCES}

Agroscope. 2015. Feeding Recommendations and Nutrient Tables for Ruminants (in German). Online Version. Accessed July 23, 2015. http://www.agroscope.admin.ch/futtermitteldatenbank/04834/.

Aguerre, M. J., M. A. Wattiaux, J. M. Powell, G. A. Broderick, and C. Arndt. 2011. Effect of forage-to-concentrate ratio in dairy cow diets on emission of methane, carbon dioxide, and ammonia, lactation performance, and manure excretion. J. Dairy Sci. 94:3081-3093.

Akaike, H. 1974. A new look at the statistical model identification. IEEE Trans. Automat. Contr. 19:716-723.

Allen, M. S., and D. R. Mertens. 1988. Evaluating constraints on fiber digestion by rumen microbes. J. Nutr. 118:261-270.

AOAC International. 1995. Official Methods of Analysis. Association of Official Analytical Chemists, Arlington, VA.

Basarab, J. A., K. A. Beauchemin, V. S. Baron, K. H. Ominski, L. L. Guan, S. P. Miller, and J. J. Crowley. 2013. Reducing GHG emissions through genetic improvement for feed efficiency: effects on economically important traits and enteric methane production. Animal 7(Suppl. 2):303-315.

Bazzoli, I., M. De Marchi, A. Cecchinato, D. P. Berry, and G. Bittante. 2014. Factors associated with age at slaughter and carcass weight, price, and value of dairy cull cows. J. Dairy Sci. 97:1082-1091.

Beauchemin, K., M. Kreuzer, F. O'Mara, and T. McAllister. 2008. Nutritional management for enteric methane abatement: A review. Aust. J. Exp. Agric. 48:21-27.

Bell, M. J., P. C. Garnsworthy, A. W. Stott, and J. E. Pryce. 2015. Effects of changing cow production and fitness traits on profit and greenhouse gas emissions of UK dairy systems. J. Agric. Sci. 153:138-151. 
Benchaar, C., C. Pomar, and J. Chiquette. 2001. Evaluation of dietary strategies to reduce methane production in ruminants: A modelling approach. Can. J. Anim. Sci. 81:563-574.

Berry, D. P., and J. J. Crowley. 2013. Genetics of feed efficiency in dairy and beef cattle. J. Anim. Sci. 91:1594-1613.

Brouwer, E. 1965. Report of subcommittee on constants and factors. Pages 441-443 in Energy Metabolism of Farm Animals. Third Symposium on Energy Metabolism, EAAP Publ. no. 11. K. L. Blaxter, ed. Academic Press, London, UK.

Buehler, K., and M. Wanner. 2014. Chapter 6: Metabolic Centre of the University of Zurich and ETH Zurich (under construction). Pages 89-106 in Technical Manual on Respiration Chamber Designs. C. Pinares and G. Waghorn, ed. Ministry of Agriculture and Forestry, Wellington, New Zealand. Accessed Jul. 27, 2015. www. globalresearchalliance.org/wp-content/uploads/2012/03/GRAMAN-Facility-BestPract-2012-FINAL.pdf.

Calcagno, V. 2013. glmulti: Model selection and multimodel inference made easy. Accessed Feb. 12, 2016. http://CRAN.R-project.org/ package $=$ glmulti.

Cassidy, E. S., P. C. West, J. S. Gerber, and J. A. Foley. 2013. Redefining agricultural yields: From tonnes to people nourished per hectare. Environ. Res. Lett. 8:034015.

Coleman, J., D. P. Berry, K. M. Pierce, A. Brennan, and B. Horan. 2010. Dry matter intake and feed efficiency profiles of 3 genotypes of Holstein-Friesian within pasture-based systems of milk production. J. Dairy Sci. 93:4318-4331.

Connor, E. E. 2015. Improving feed efficiency in dairy production: Challenges and possibilities. Animal 9:395-408.

Connor, E. E., J. L. Hutchison, H. D. Norman, K. M. Olson, C. P. Van Tassell, J. M. Leith, and R. L. Baldwin. 2013. Use of residual feed intake in Holsteins during early lactation shows potential to improve feed efficiency through genetic selection. J. Anim. Sci. 91:3978-3988.

Dado, R. G., and M. S. Allen. 1994. Variation in and relationships among feeding, chewing, and drinking variables for lactating dairy cows. J. Dairy Sci. 77:132-144.

FAOSTAT. 2014. Emissions - Agriculture: Enteric Fermentation. Accessed Jul. 27, 2015. http://faostat3.fao.org/faostat-gateway/go/ to/browse/G1/GE/E.

Fox, J. 2003. Effect displays in R for generalised linear models. J. Stat. Softw. 8:1-27.

Franz, R., C. R. Soliva, M. Kreuzer, P. Steuer, J. Hummel, and M. Clauss. 2010. Methane production in relation to body mass of ruminants and equids. Evol. Ecol. Res. 12:727-738.

Goopy, J. P., A. Donaldson, R. Hegarty, P. E. Vercoe, F. Haynes, M. Barnett, and V. H. Oddy. 2014. Low-methane yield sheep have smaller rumens and shorter rumen retention time. Br. J. Nutr. 111:578-585.

Graham, N. McC. 1980. Variation in energy and nitrogen utilization by sheep between weaning and maturity. Aust. J. Agric. Res. 31:335-345.

Grandl, F., S. P. Luzi, M. Furger, J. O. Zeitz, F. Leiber, S. Ortmann, M. Clauss, M. Kreuzer, and A. Schwarm. 2016. Biological implications of longevity in dairy cows: 1 . Changes in feed intake, feeding behavior, and digestion with age. J. Dairy Sci. 99:3457-3471. http://dx.doi.org/10.3168/jds.2015-10261.

Gruber, L., F. J. Schwarz, D. Erdin, B. Fischer, H. Spiekers, H. Steingaß, U. Meyer, A. Chassot, T. Jilg, A. Obermaier, and T. Guggenberger. 2004. Vorhersage der Futteraufnahme von Milchkühen - Datenbasis von 10 Forschungs- und Universitätsinstituten Deutschlands, Österreichs und der Schweiz (Prediction of feed intake of dairy cows - database of 10 research and university institutes of Germany, Austria and Switzerland; in German). Pages 484-504 in VDLUFA-Schriftenreihe, Band 60 - Kongressband 2004. VDLUFA-Verlag, Darmstadt, Germany. Accessed Feb. 12, 2016. www.vdlufa.de/download/Kongressband_2004.pdf.

Guilloteau, P., R. Zabielski, and J. W. Blum. 2009. Gastrointestinal tract and digestion in the young ruminant: ontogenesis, adaptations, consequences and manipulations. J. Physiol. Pharmacol. 60:37-46.
Hare, E., H. D. Norman, and J. R. Wright. 2006. Survival rates and productive herd life of dairy cattle in the United States. J. Dairy Sci. 89:3713-3720.

Hegarty, R. S., J. P. Goopy, R. M. Herd, and B. McCorkell. 2007. Cattle selected for lower residual feed intake have reduced daily methane production. J. Anim. Sci. 85:1479-1486.

Herd, R. M., and P. F. Arthur. 2009. Physiological basis for residual feed intake. J. Anim. Sci. 87:E64-E71.

Hindrichsen, I. K., H.-R. Wettstein, A. Machmüller, and M. Kreuzer. 2006. Methane emission, nutrient degradation and nitrogen turnover in dairy cows and their slurry at different milk production scenarios with and without concentrate supplementation. Agric. Ecosyst. Environ. 113:150-161.

Hironaka, R., G. W. Mathison, B. K. Kerrigan, and I. Vlach. 1996. The effect of pelleting of alfalfa hay on methane production and digestibility by steers. Sci. Total Environ. 180:221-227.

Horn, M., W. Knaus, L. Kirner, and A. Steinwidder. 2012. Economic evaluation of longevity in organic dairy cows. Org. Agric. 2:127143

Hristov, A. N., J. Oh, J. L. Firkins, J. Dijkstra, E. Kebreab, G. Waghorn, H. P. S. Makkar, A. T. Adesogan, W. Yang, C. Lee, P. J. Gerber, B. Henderson, and J. M. Tricarico. 2013a. Mitigation of methane and nitrous oxide emissions from animal operations: I. A review of enteric methane mitigation options. J. Anim. Sci. 91:5045-5069.

Hristov, A. N., T. Ott, J. Tricarico, A. Rotz, G. Waghorn, A. T. Adesogan, J. Dijkstra, F. Montes, J. Oh, E. Kebreab, S. J. Oosting, P. J. Gerber, B. Henderson, H. P. S. Makkar, and J. L. Firkins. 2013b. Mitigation of methane and nitrous oxide emissions from animal operations: III. A review of animal management mitigation options. J. Anim. Sci. 91:5095-5113.

IPCC (Intergovernmental Panel on Climate Change). 2006. Guidelines for National Greenhouse Gas Inventories. Vol. 4. Agriculture, Forestry and Other Land Use. Ch. 10. Emissions from Livestock and Manure Management. 10.1-10.87. Accessed Jul. 27, 2015. http:// www.ipcc-nggip.iges.or.jp/public/2006gl/vol4.html.

Janssen, P. H. 2010. Influence of hydrogen on rumen methane formation and fermentation balances through microbial growth kinetics and fermentation thermodynamics. Anim. Feed Sci. Technol. 160:1-22

Jensen, L. M., N. I. Nielsen, E. Nadeau, B. Markussen, and P. Nørgaard. 2015. Evaluation of five models predicting feed intake by dairy cows fed total mixed rations. Livest. Sci. 176:91-103.

Jiao, H., T. Yan, D. A. Wills, A. F. Carson, and D. A. McDowell. 2014. Development of prediction models for quantification of total methane emission from enteric fermentation of young Holstein cattle at various ages. Agric. Ecosyst. Environ. 183:160-166.

Knapp, J. R., G. L. Laur, P. A. Vadas, W. P. Weiss, and J. M. Tricarico. 2014. Invited review: Enteric methane in dairy cattle production: Quantifying the opportunities and impact of reducing emissions. J. Dairy Sci. 97:3231-3261.

Knight, T. W., H. Clark, G. Molano, S. V. Maclean, and D. S. Villacorta. 2008b. Determination of methane emissions per unit of intake in young dairy heifers compared to mature cows. MAF Technical Paper. 2011/83. Ministry of Agriculture and Forestry, Wellington, New Zealand.

Knight, T. W., G. Molano, H. Clark, and A. Cavanagh. 2008a. Methane emissions from weaned lambs measured at 13,17, 25 and 35 weeks of age compared with mature ewes consuming a fresh forage diet. Aust. J. Exp. Agric. 48:240-243.

Leiber, F., K. Dorn, J. K. Probst, A. Isensee, N. Ackermann, A. Kuhn, and A. Spengler Neff. 2015. Concentrate reduction and sequential roughage offer to dairy cows: Effects on milk protein yield, protein efficiency and milk quality. J. Dairy Res. 82:272-278.

Lubritz, D. L., K. Forrest, and O. W. Robison. 1989. Age of cow and age of dam effects on milk production of Hereford cows. J. Anim. Sci. 67:2544-2549.

Macdonald, K. A., J. E. Pryce, R. J. Spelman, S. R. Davis, W. J. Wales, G. C. Waghorn, Y. J. Williams, L. C. Marett, and B. J. Hayes. 2014. Holstein-Friesian calves selected for divergence in re- 
sidual feed intake during growth exhibited significant but reduced residual feed intake divergence in their first lactation. J. Dairy Sci. 97:1427-1435.

Maekawa, M., K. A. Beauchemin, and D. A. Christensen. 2002. Chewing activity, saliva production, and ruminal $\mathrm{pH}$ of primiparous and multiparous lactating dairy cows. J. Dairy Sci. 85:1176-1182.

Molano, G., H. Clark, T. W. Knight, and A. Cavanagh. 2006. Methane emissions from growing beef cattle grazing hill country pasture. Proc. N.Z. Soc. Anim. Prod. 66:172-175.

Moss, A., J.-P. Jouany, and J. Newbold. 2000. Methane production by ruminants: Its contribution to global warming. Ann. Zootech. $49: 231-253$.

Müller, D. W. H., D. Codron, C. Meloro, A. Munn, A. Schwarm, J. Hummel, and M. Clauss. 2013. Assessing the Jarman-Bell Principle: Scaling of intake, digestibility, retention time and gut fill with body mass in mammalian herbivores. Comp. Biochem. Physiol. A Mol. Integr. Physiol. 164:129-140.

Nkrumah, J. D., E. K. Okine, G. W. Mathison, K. Schmid, C. Li, J. A. Basarab, M. A. Price, Z. Wang, and S. S. Moore. 2006. Relationships of feedlot feed efficiency, performance, and feeding behavior with metabolic rate, methane production, and energy partitioning in beef cattle. J. Anim. Sci. 84:145-153.

O'Brien, D., L. Shalloo, J. Patton, F. Buckley, C. Grainger, and M. Wallace. 2012. A life cycle assessment of seasonal grass-based and confinement dairy farms. Agric. Syst. 107:33-46.

Okine, E. K., G. W. Mathison, and R. T. Hardin. 1989. Effects of changes in frequency of reticular contractions on fluid and particulate passage rates in cattle. J. Anim. Sci. 67:3388-3396.

Pinares-Patiño, C. S., S. M. Hickey, E. A. Young, K. G. Dodds, S. MacLean, G. Molano, E. Sandoval, H. Kjestrup, R. Harland, C. Hunt, N. K. Pickering, and J. C. McEwan. 2013. Heritability estimates of methane emissions from sheep. Animal 7(Suppl. 2):316-321.

Pinares-Patiño, C. S., G. C. Waghorn, A. Machmüller, B. Vlaming, G. Molano, A. Cavanagh, and H. Clark. 2007. Methane emissions and digestive physiology of non-lactating dairy cows fed pasture forage. Can. J. Anim. Sci. 87:601-613.

R Core Team. 2015. R: A Language and Environment for Statistical Computing. R Foundation for Statistical Computing, Vienna, Austria.

Ramírez-Restrepo, C. A., H. Clark, and S. Muetzel. 2015. Methane emissions from young and mature dairy cattle. Anim. Prod. Sci. http://dx.doi.org/10.1071/AN15102.

Richardson, E. C., and R. M. Herd. 2004. Biological basis for variation in residual feed intake in beef cattle. 2. Synthesis of results following divergent selection. Aust. J. Exp. Agric. 44:431-440.

Swainson, N. M., S. O. Hoskin, H. Clark, and N. Lopez-Villalobos. 2007. The effect of age on methane emissions from young, weaned red deer (Cervus elaphus) stags grazing perennial-ryegrass (Lolium perenne)-based pasture. N.Z. J. Sci. Technol. 50:407-416.

Symonds, M. R. E., and A. Moussalli. 2011. A brief guide to model selection, multimodel inference and model averaging in behavioural ecology using Akaike's information criterion. Behav. Ecol. Sociobiol. 63:13-21.

Thomassen, M. A., K. J. van Calker, M. C. J. Smits, G. L. Iepema, and I. J. M. de Boer. 2008. Life cycle assessment of conventional and organic milk production in the Netherlands. Agric. Syst. 96:95-107.

Ulyatt, M. J., D. W. Dellow, A. John, C. S. W. Reid, and G. C. Waghorn. 1986. Contribution of chewing during eating and rumination to the clearance of digesta from the ruminoreticulum. Pages 498-515 in Control of Digestion and Metabolism in Ruminants: Proc. 6th Int. Symp. Ruminant Physiology. L. P. Milligan, W. L. Grovum, and A. Dobson, ed. Prentice-Hall, Englewood Cliffs, NJ.

Zeitz, J. O., C. R. Soliva, and M. Kreuzer. 2012. Swiss diet types for cattle: how accurately are they reflected by the Intergovernmental Panel on Climate Change default values? J. Integr. Environ. Sci. 9:199-216. 


\section{APPENDIX}

The predicted dry matter intake (PDMI) required for the calculation of RFI (difference between observed DMI in the experiment and PDMI) in the present study was obtained using equation 2 from Gruber et al. (2004), who analyzed data generated in similar production systems (breeds, feed sources, climate). In detail, the PDMI was calculated as

$$
\begin{gathered}
\mathrm{PDMI}=\mu+\mathrm{C} \times \mathrm{B}+\mathrm{LNo}+\mathrm{LDay}+\beta_{1} \mathrm{BW} \\
+\beta_{2} \mathrm{MY}+\beta_{3} \mathrm{CONC}+\beta_{4} \mathrm{NE}_{\mathrm{Lf}}+\beta_{5} \mathrm{Hay}_{\mathrm{f}} \\
+\beta_{6} \mathrm{Corn}_{\mathrm{f}}+\beta_{7} \mathrm{CP} / \mathrm{NE}_{\mathrm{L}}+\beta_{8} \mathrm{CP} / \mathrm{NE}_{\mathrm{L}}{ }^{2},
\end{gathered}
$$

where $\mu$ intercept; coefficients for the effects of the C $\times \mathrm{B}=$ interaction of country and breed; LNo = lactation number; LDay $=$ DIM; $\beta_{1 \ldots 8}$ regression coefficients for $\mathrm{BW}, \mathrm{MY}=$ daily milk yield, $\mathrm{CONC}=\mathrm{kg}$ of $\mathrm{DM}$ of concentrate per day, $\mathrm{NE}_{\mathrm{Lf}}=\mathrm{NE}_{\mathrm{L}}$ content of forage $\mathrm{DM}, \mathrm{Hay}_{\mathrm{f}}=$ hay proportion of forage DM, $\mathrm{Corn}_{\mathrm{f}}=$ corn silage proportion of forage $\mathrm{DM}, \mathrm{CP} / \mathrm{NE}_{\mathrm{L}}=\mathrm{CP}$-to- $\mathrm{NE}_{\mathrm{L}}$ ratio of the diet (linear and quadratic). The calculation of the effects and regression coefficients as given by Gruber et al. (2004) are listed in Table A1. The PDMI was finally corrected based on the validation of the prediction equation according to Gruber et al. (2004) resulting in the corrected PDMI $\left(\mathbf{P D M I}_{\text {corr }}\right)$ with the following equation:

$$
\mathrm{PDMI}_{\text {corr }}=0.38+0.932 \times \text { PDMI } .
$$

The $\mathrm{PDMI}_{\text {corr }}$ was used for the calculation of RFI (i.e.,

\begin{tabular}{|c|c|c|c|}
\hline Effect & Unit & Parameter & $\begin{array}{l}\text { Parameter } \\
\text { value }\end{array}$ \\
\hline Intercept & \multirow{4}{*}{ Number } & & -0.959 \\
\hline \multirow[t]{3}{*}{ Fixed effect for LNo } & & 1 & -0.767 \\
\hline & & $2-3$ & 0.261 \\
\hline & & $\geq 4$ & 0 \\
\hline \multirow{3}{*}{$\begin{array}{l}\text { Fixed effect for LDay } \\
\text { Model: } a+b \times(1-\exp (-c \times \text { LDay }))\end{array}$} & \multirow[t]{3}{*}{ d } & $a$ & -4.224 \\
\hline & & $b$ & 4.088 \\
\hline & & $c$ & 0.01583 \\
\hline \multirow{3}{*}{$\begin{array}{l}\text { Regression coefficient forBW } \\
\text { Model: } \mathrm{a}+\mathrm{b} \times \text { LDay }+\mathrm{c} \times \text { LDay }^{2}\end{array}$} & \multirow[t]{3}{*}{$\mathrm{kg}$} & $a$ & 0.0142 \\
\hline & & $b$ & $-4.31 \cdot 10^{-5}$ \\
\hline & & $c$ & $7.63 \cdot 10^{-8}$ \\
\hline \multirow{3}{*}{$\begin{array}{l}\text { Regression coefficient for MY } \\
\text { Model: } \mathrm{a}+\mathrm{b} \times \mathrm{LDay}+\mathrm{c} \times \mathrm{LDay}^{2}\end{array}$} & \multirow[t]{3}{*}{$\mathrm{kg} / \mathrm{d}$} & $a$ & 0.0823 \\
\hline & & $b$ & $8.151 \cdot 10^{-4}$ \\
\hline & & $c$ & $-1.065 \cdot 10^{-6}$ \\
\hline \multirow{3}{*}{$\begin{array}{l}\text { Regression coefficents for CONC } \\
\text { Model: } a+b \times \text { LDay }+\mathrm{c} \times \text { LDay }^{2}\end{array}$} & \multirow{3}{*}{$\mathrm{kg}$ of $\mathrm{DM} / \mathrm{d}$} & $a$ & 0.6856 \\
\hline & & $b$ & $-2.1353 \cdot 10^{-3}$ \\
\hline & & $c$ & $3.8023 \cdot 10^{-6}$ \\
\hline Regression coefficients for $\mathrm{NE}_{\mathrm{Lf}}$ & $\mathrm{MJ} / \mathrm{kg}$ of $\mathrm{DM}$ & & 0.983 \\
\hline Regression coefficients for $\mathrm{Hay}_{\mathrm{f}}$ & $\%$ of forage DM & & 0.01154 \\
\hline Regression coefficients for Corn $_{f}$ & $\%$ of forage DM & & 0.00699 \\
\hline \multirow[t]{2}{*}{ Regression coefficients for $\mathrm{CP} / \mathrm{NE}_{\mathrm{L}}$} & $\mathrm{g} / \mathrm{MJ}^{2}$ & $\mathrm{CP} / \mathrm{NE}_{\mathrm{L}_{2}}$ & 0.2053 \\
\hline & $\mathrm{g} / \mathrm{MJ}^{2}$ & $\mathrm{CP} / \mathrm{NE}_{\mathrm{L}}^{2}$ & $-2.266 \cdot 10^{-3}$ \\
\hline
\end{tabular}
the difference between the observed DMI and $\mathrm{PDMI}_{\text {corr }}$ in the present study).

Table A1. Effects and regression coefficients and their calculation as given by Gruber et al. (2004) 